\title{
Sim à garantia para a infância $e$ juventude do exercício dos direitos elementares da pessoa humana. Não à diminuição da imputabilidade penal
}

\author{
Olympio de Sá Sotto Maior Neto
}

\begin{abstract}
RESUMO
$\mathrm{O}$ artigo argumenta contra a diminuição da imputabilidade penal aos menores de dezoito anos. Refere-se ao dever funcional do Ministério Público de promover a materialização dos direitos individuais, coletivos e difusos relativos à infância e juventude. Destaca que (a) os menores de dezoito anos praticantes de comportamento previsto na legislação como crime ou contravenção têm o direito fundamental de estar sujeito às normas do Estatuto da Criança e do Adolescente; (b) deve-se respeitar as crianças e adolescentes como pessoas em peculiar fase de desenvolvimento; (c) a prevenção integral é a meta: medidas socioeducativas, principalmente a de liberdade assistida para o adolescente autor de algum delito, apresentam as melhores condições de êxito quando direcionadas a interferir positivamente na realidade familiar e social do adolescente, resgatando as suas potencialidades.

Palavras-chave: imputabilidade penal, Estatuto da Criança e do Adolescente, medida socioeducativa.
\end{abstract}

\begin{abstract}
This paper contradicts less penal imputation to 18-year-old minors. It refers to the duty of the Public Ministery to ensure individual rights, and collective and diffusive rights concerning children and adolescents as well. It emphasizes the following issues: a)18-year-old minors have criminal behavior which could be ruled according to our legislation but instead they are judged under the Statute of Children and Teenagers'; (b) children and teenagers should be respected as people at a peculiar developing period of time; (c) integral prevention should be the case: social-educative measures, special assistance given to criminal adolescent who was set free, so as conditions for this teenager to be positively re-integrated within his/her familiar and social reality, having his/her potentials back.

Key-words: penal imputability, Statute of Children and Teeagers', social-educative measures.
\end{abstract}

\section{Introdução}

\begin{abstract}
Idealizo a transformação do Ministério Público em Ministério Social. Um Ministério Social em ação, ação mesmo, com fins e também meios próprios contra não só as ilegalidades mas, principalmente, contra as injustiças. Os privilégios, os pesos e medidas desiguais são inconstitucionais. Assim, o Ministério Público evoluiria para assumir a responsabilidade daquilo que é mais significativo na ordem jurídica - a paz social pela justiça social, tarefa máxima da democracia na atual conjuntura da humanidade. O Ministério Público Social procurará dar a cada um o que é seu, mas, sobretudo, acudir a quem nada tem de seu, a quem quer, mas não pode, viver honestamente, a quem, apesar de tudo, não prejudique ninguém. O Procurador-Geral será mesmo geral e tornará prática e total a expressão mais profunda de nossa nomenclatura funcional promotor de justiça. Um Ministério Público Social promoverá a justiça social, cuidará dela e não só de uma justiça pública, estatal, oficial. A ordem jurídica seria adaptada aos dramas contemporâneos. A primazia nos benefícios pertenceria aos mais necessitados. A tranqüilidade de consciência do Ministério Público depende de avanço que ele mesmo executará.
\end{abstract}

Roberto Lyra, "príncipe dos Promotores de Justiça", 1952.

O tema pertinente à resposta que se pretenda dar aos adolescentes autores de ato infracional (que, digase desde logo, deve ser exatamente aquela prevista no Estatuto da Criança e do Adolescente e não a advinda do Direito Penal), diz respeito, de forma inafastável, aos integrantes do Ministério Público. É que, de um lado, eles exercem parcela da soberania do Estado enquanto titulares exclusivos da ação penal pública e, de outro, têm dever funcional de promover a materialização dos direitos individuais, coletivos e difusos relativos à 
infância e juventude. Mais que isso: por ser função institucional do Ministério Público a defesa do regime democrático, estão obrigados a permanente reflexão acerca do conteúdo ideológico das normas jurídicas de modo a impedir que o Direito seja utilizado para praticar injustiças. A existência de responsabilidade política, ética e profissional a impulsionar o cumprimento do papel de efetivos defensores da sociedade brasileira e do estado de Direito democrático, serviu como fator determinante para a apresentação da presente tese ao XIII Congresso Nacional do Ministério Público, objetivando então colher a manifestação de todos os promotores e Procuradores de Justiça do Brasil no sentido da manutenção da imputabilidade penal - conforme previsto no artigo 288, da Constituição Federal - somente a partir dos dezoito anos de idade. Também, concluir que as disposições do Estatuto da Criança e do Adolescente restam suficientes ao propósito de se responder com justiça à prática de atos infracionais por adolescentes.

O primeiro ponto que deve ser ressaltado - e que importa, na prática, fulminar com qualquer proposta de emenda constitucional direcionada à diminuição da imputabilidade penal - contempla a conclusão de que a imputabilidade penal somente a partir dos dezoito anos, trazida à condição de cânone constitucional pela Assembléia Nacional Constituinte de 1988, corresponde à cláusula pétrea e, por isso mesmo, insuscetível de modificação por via de emenda, conforme comando do artigo 60, 4" da Constituição Federal (assim: "Não será objeto de deliberação a proposta de emenda constitucional tendente a abolir: [...] IV - os direitos e garantias individuais"). Embora topograficamente distanciada do artigo $5^{\circ}$, da Constituição Federal (pois, afinal, pela primeira vez na história constitucional brasileira destinou-se um capítulo exclusivo para tratar da família, da criança, do adolescente e do idoso), não há dúvida de que a regra do artigo 228, da Constituição Federal, apresenta natureza análoga aos direitos, liberdades e garantias, como anota Gomes Canotilho, "os direitos de natureza análoga são direitos que, embora não referidos no catálogo dos direitos, liberdades e garantias, beneficiam de um regime jurídico constitucional idêntico aos destes" ou, na observação de Alexandre de Moraes:

a grande novidade do referido artigo 60 está na inclusão, entre as limitações ao poder de reforma da Constituição, dos direitos inerentes ao exercício da democracia representativa e dos direitos e garantias individuais, que por não se encontrarem restritos ao rol do artigo $5^{\circ}$, resguardam um conjunto mais amplo de direitos constitucionais de caráter individual dispersos no texto da carta Magna).

Vale dizer, os menores de dezoito anos, a quem se atribua a prática de um comportamento previsto na legislação como crime ou contravenção, têm o direito fundamental (que se traduz também em garantia decorrente do princípio constitucional da proteção especial) de estar sujeito às normas do Estatuto da Criança e do Adolescente (recebendo, se for o caso e como resposta à sua conduta ilícita, as medidas socioeducativas) e afastados, portanto, das sanções do direito penal. É este, inclusive, o pensamento do Fórum DCA (Fórum Nacional de Defesa da Criança e do Adolescente).

Mas mesmo que assim não fosse, deve-se considerar que as discussões sobre tal matéria se relacionam, em regra, ao raciocínio equivocado de que não há previsão legal para responsabilizar os adolescentes autores de ato infracional (argumentando alguns até que a própria lei, isto é, o Estatuto da Criança e do Adolescente, estaria a proteger - quando não a estimular - a prática de atos anti-sociais pelos adolescentes) e assim, culminando com proposta perversa na direção da diminuição da imputabilidade penal, como se tão só a repressão penal fosse capaz de responder às intricadas condições determinantes da conduta desviante dos adolescentes ou de superar situações que são, via de regra, de ordem estritamente social. No propósito de reflexão séria, adequadamente multidisciplinar e ideologicamente correta, a análise inicial a se fazer passa pela perfeita identificação de quem se está falando, ou seja, das crianças e adolescentes que estão a experimentar situação de absoluto descaso, de secular desassistência e de omissão criminosa por parte do Estado Brasileiro. Não se trata aqui, portanto, do infrator da França, Suíça ou Suécia, mas sim daquele que integra a infância e juventude de um país cuja marca social mais significativa ( e trágica) é a má distribuição das riquezas, alcançando, segundo dados do Banco Mundial, o infeliz status de campeão mundial das desigualdades sociais (um país extremamente rico, com uma população absolutamente pobre). Se é constatada, de um lado, a concentração absurda de renda nas mãos de poucas pessoas, inevitavelmente, do outro lado dessa mesma moeda, encontra-se cunhada a face da grande maioria da população marginalizada, isto é, à margem dos benefícios produzidos pela sociedade. Nesse passo, então, é necessário - e indispensável - reconhecer a proximidade que existe entre a marginalidade e a delinqüência. Não se trata, evidentemente, de repetir teorias determinantes de indesejável etiquetamento social, tão combatidas pela criminologia crítica, que se insurge corretamente contra o estabelecimento de um vínculo indissolúvel entre a pobreza e a criminalidade. Ou seja, não se quer dizer que todos os pobres sejam criminosos, porque advindas desse 
raciocínio falso são as ações policiais ilegais, como ocorreu em Vigário Geral, quando pessoas ligadas às forças que deveriam estar prestando segurança à sociedade adentram em casa de favelados e matam todas as pessoas lá encontradas, partindo do pressuposto absurdo de que o homem morador da favela é sempre um bandido, uma vez que a pobreza estaria a criar este vínculo indissolúvel com a criminalidade. Há que se constatar que o fato verdadeiro da existência de crianças e adolescentes que experimentam condições reais de vida tão adversas, insuperáveis pelos meios tidos como legais ou legítimos, acabam impulsionados no sentido da criminalidade. Esta é a conclusão que não pode ser afastada, sob pena de reprodução do mito - e chavão fácil - do livre arbítrio informador do direito criminal.

A lição mais importante aprendida em quase vinte e três anos de Ministério Público foi a de que a realidade social e a Justiça devem estar presentes em todos os momentos da vida do Direito. A atuação do jurista despreocupada com esses conteúdos se traduz em comportamento profissional meramente burocrático, que, antes de ter o condão de auxiliar na construção de nova ordem social, apresenta efeito contrário, auxiliando na manutenção do status quo - injusto - vigente. Nesse aspecto, assente-se que esta atividade profissional, centrada apenas na proposta de responder às conseqüências dos fatos criminosos, significa parca colaboração para o propósito de ver instalada uma sociedade progressivamente melhor e mais justa. Tão só encaminhar para as cadeias públicas ou para o sistema de segregação oficial os autores de fatos criminosos não auxilia em nada - afora uma imaginada prevenção geral - a tarefa de impedir ou prevenir a prática de novos delitos. Daí a preocupação com a realidade social brasileira ser o ponto central da reflexão vinculada à violência praticada por e contra crianças e adolescentes, conjugando-se o pensamento de que a infância e juventude (e suas famílias) estão visceralmente ligados a uma situação de miserabilidade. Segundo estatísticas do IBGE, cerca de 56\% (cinqüenta e seis por cento) dos brasileiros integram famílias cuja renda per capita é inferior a meio salário mínimo (que, diga-se, mesmo quando percebido por inteiro se mostra insuficiente para atender às necessidades básicas do trabalhador e de sua família, correspondendo hoje, inclusive, a 18\% (dezoito por cento) do seu valor real quando instituído em 1940). Vale lembrar que existe no país cerca de trinta milhões de pessoas (cidadãos?!) vivendo em situação de indigência, ou seja, abaixo da linha da pobreza. Nesse quadro social, evidente resta que o primeiro enfrentamento no sentido de evitar a criminalidade e a violência infanto-juvenil deve buscar a superação da condição de marginal (insista-se, à margem dos benefícios produzidos pela sociedade) infelizmente vivenciada pela maioria das crianças e adolescentes brasileiros. Evitando-se a marginalidade, além de estar cumprindo os ditames do estatuto da Criança e do Adolescente (assim como de todos os demais documentos internacionais pertinentes aos direitos fundamentais das crianças e adolescentes), certamente se estará impedindo o aumento do índice de delinqüência infantojuvenil. No momento em que o Poder Público responder concretamente ao seu dever institucional de assegurar a todas as crianças e adolescentes - com prioridade absoluta - o exercício dos direitos elementares da cidadania, indiscutivelmente se caminhará para o contexto real inibidor da marginalidade e, de conseqüência, determinante de efetiva prevenção à criminalidade.

Outro ponto que comparece merecedor de destaque, pertinente à filosofia que permeia as normas do Estatuto da Criança e do Adolescente e consistente na regra geral, é o de que se deve respeitar as crianças e os adolescentes enquanto pessoas em peculiar fase de desenvolvimento. Referente ao adolescente autor de ato infracional, tal máxima deve se traduzir em visão interdisciplinar que englobe os avanços científicos na área médica, de modo a se identificar os comportamentos que seriam, por assim dizer, próprios na adolescência. Tais estudos indicam coexistirem na denominada "síndrome da adolescência normal", além da reprodução dos comportamentos e usos do grupo (a conduta social, a fala, a vestimenta etc.), também o insurgimento contra os valores estabelecidos pela sociedade. Já se ouviu a crítica no sentido de que os autores de atos infracionais são aqui referidos como se todos fossem santos. Bem pelo contrário, fala-se na perspectiva de que nenhum deles é santo, porque ninguém passa pela adolescência sem a prática de atos anti-sociais ou infracionais. Ora, para determinadas faixas sociais, a ocorrência de uma crise na adolescência é facilmente reconhecida e aceita, como o demonstra o dia-a-dia nos Juizados da Infância e da Juventude, bem assim em outros espaços de atendimento e/ou tratamento dos adolescentes. Para estes, admite-se que referida fase crítica propicia reflexos dos conflitos internos na conduta cotidiana e desviante, seja no âmbito familiar ou escolar, ou ainda no seu próprio relacionamento com os demais segmentos sociais. Todavia, os filhos das classes populares, das famílias empobrecidas e despossuídas, não encontram essa mesma compreensão. Já estes, freqüentemente, são vistos pela sociedade como dotados de natureza perversa, de má índole, sendo considerados irrecuperáveis, como os bandidos em relação aos quais o meio social precisa se precaver. $\mathrm{Na}$ realidade, com apoio no estudo e outros ramos do conhecimento científico que não o Direito, deve-se reconhecer aos adolescentes, sejam eles da classe social que forem, a possibilidade - absolutamente normal de se insurgirem e violarem as regras estabelecidas pela sociedade. Há até uma música que fala disso, do 
rebelde sem causa, que materialmente tem tudo, recebe toda a atenção e afeto dos pais, conta com a consideração social e, mesmo assim, revolta-se. Se os filhos de classes privilegiadas - vale dizer - os que possuem oportunidade de vida digna e de melhor alcance da felicidade - rebelam-se, não é difícil imaginar que, com muito maior razão, os filhos das classes excluídas no contexto social também se revoltem contra a estrutura injusta que lhes é imposta. Quando, no momento da elaboração do estatuto da criança e do Adolescente, discutia-se a questão relativa à possibilidade de aplicação da medida socioeducativa de internamento em razão do descumprimento reiterado e injustificado da medida judicial anteriormente estabelecida (conforme regra afinal prevista no artigo 122, inc. III), foi argumentado que este internamento seria necessário, até por três meses, para que o adolescente, descumpridor das determinações judiciais, levasse um susto e nunca mais desatendesse a sentença da Justiça da Infância e da Juventude. Divergindo de tal naipe de raciocínio, observa-se que só defende este ponto de vista quem tem certeza de que os próprios filhos jamais serão encaminhados para uma unidade de internação, onde o susto pelo qual se quer que os filhos dos outros passem pode implicar na prática de violências físicas, psicológicas e sexuais. A idéia a predominar quando se analisa a imposição de qualquer medida a autor de ato infracional é a de que, se a medida é justa, deve ser aplicada a qualquer adolescente, independentemente da classe social a que ele pertença.

Como assunto correlato, é de se destacar que a defesa da diminuição da imputabilidade penal, via de regra, apresenta o argumento de ser inviável sustentar que um adolescente de 16 ou 17 anos não tenha conhecimento do que seja certo ou errado. Trata-se, sabe-se bem, de um raciocínio equivocado, porquanto a imputabilidade não se estabelece tão-só a partir do discernimento, da capacidade de reconhecer o caráter ilícito do fato. Uma criança de oito anos de idade, por exemplo, pode ter a consciência da ilicitude de sua conduta e, portanto, discernimento, mas não se concebe que seja ela considerada penalmente imputável. Assim é porque, além da capacidade de entender o caráter ilícito do fato, para a imputabilidade é necessária a capacidade de se determinar de acordo com esse entendimento. Também o adolescente, por passar por fase crítica na formação de sua personalidade, sofre extraordinárias e negativas influências no que tange ao componente volitivo da imputabilidade, de modo a não se poder considerá-lo com capacidade de determinação conforme eventual consciência de ilicitude. As infrações decorrentes das condições de imaturidade bio-psicológica reclamam a intervenção no sentido da orientação, assistência e reabilitação, buscando-se alcançar o inerente potencial dirigido à sociedade. Essa linha de pensamento é que levou o legislador na nova Parte Geral do Código Penal (Lei n. ${ }^{\circ}$ 7.209/84) a manter o preceito da inimputabilidade para os menores de 18 anos, constando da exposição de motivos o seguinte:

\begin{abstract}
Manteve o Projeto a inimputabilidade penal ao menor de 18 anos. Trata-se de opção apoiada em critérios de Política Criminal. Os que preconizam a redução do limite, sob a justificativa da criminalidade crescente, que a cada dia recruta maior número de menores, não consideram a circunstância de que o menor, ser ainda incompleto, é naturalmente anti-social na medida em que não é solicitado ou instruído. $\mathrm{O}$ reajustamento do processo de formação de caráter deve ser cometido à educação, não à pena criminal. De resto, com a legislação de menores recentemente editada, dispõe o Estado dos instrumentos necessários ao afastamento do jovem delinqüente, menor de 18 anos, do convívio social, sem sua necessária submissão ao tratamento do delinqüente adulto, expondo-o à contaminação carcerária.
\end{abstract}

Nesta quadra, vale enfatizar a importância das medidas socioeducativas, ao tempo em que significam a resposta da lei - severa, mas justa - à prática de atos infracionais por adolescentes. Tanto quanto ocorreria com um adulto que comete um ilícito penal, também o adolescente praticante de ato infracional será responsabilizado pela sua conduta, ao contrário do que indevidamente se difunde. Como se sabe, as medidas socioeducativas vão desde a advertência, passando pela obrigação de reparar o dano, prestação de serviços à comunidade ou inserção no regime de liberdade assistida, até restritivas ou privativas de liberdade (semiliberdade e internação). Já foi dito que o esforço - de todos os profissionais atuantes na área da infância e juventude - deve visar nesse momento a efetivação dos programas capazes de garantir a execução das medidas socioeducativas, principalmente a de liberdade assistida, uma vez que apresenta as melhores condições de êxito quando direcionada a interferir positivamente na realidade familiar e social do adolescente, tencionando resgatar, mediante apoio técnico, as suas potencialidades (aliás, o acompanhamento, auxílio e orientação, a promoção social do adolescente e de sua família, bem como a inserção no sistema educacional e no mercado de trabalho, certamente importarão o estabelecimento de projeto de vida capaz de produzir ruptura com a prática de delitos, reforçados que restarão os vínculos entre o adolescente, seu grupo de convivência e a comunidade). As medidas de advertência, obrigação de reparar o dano e prestação de serviços à comunidade indicam a nítida prevalência do caráter educativo ao punitivo. É que as técnicas educativas 
voltadas à autocrítica e à reparação do dano se mostram muito mais eficazes, já que produzem no sujeito infrator a possibilidade de reafirmação dos valores éticos-sociais, tratando-o como alguém que pode se transformar, que é capaz de aprender moralmente e se modificar (as técnicas de conteúdo punitivo, segundo as teorias da aprendizagem, eliminam o comportamento somente no instante em que a punição ocorre, reaparecendo porém, e com toda a força, tão logo os controles aversivos sejam retirados). Quanto à internação, carece a sua aplicação de reflexão profunda, porquanto se apresenta como a medida socioeducativa com as piores condições para produzir resultados positivos. Com efeito, a partir da segregação e da inexistência de um projeto de vida, os adolescentes internados acabam ainda mais distantes da possibilidade de um desenvolvimento sadio. Privados de liberdade, convivendo em ambientes de regras promíscuos e aprendendo as normas próprias dos grupos marginais (especialmente no que tange a responder com violências aos conflitos do cotidiano) a probabilidade (quase absoluta) é de que os adolescentes acabem absorvendo a chamada identidade do infrator, passando a se reconhecer, sim, como pessoas cuja história de vida, passada e futura, resta indestrutivelmente ligada à delinqüência (os irrecuperáveis, como dizem deles). Dessa forma, quando do desinternamento, certamente se estará distante de cidadãos com categoria piorada, ainda mais predispostos a condutas violentas e anti-sociais. Daí a importância de se observar atentamente as novas regras legais referentes à internação, especialmente aquelas que dizem respeito à excepcionalidade da medida, sua brevidade e, a todo tempo, o respeito 'a condição peculiar de pessoa em desenvolvimento (de ressaltar também o novo elenco de direitos pertinentes ao adolescente internado, conforme disposto do artigo 124 do ECA). Na verdade, ao se concordar com ela, sempre se fará numa perspectiva de que venha a servir, como dizem os laudos técnicos, para introjeção de valores éticos e sociais, na trilha da emenda e da ressocialização. Mas a realidade é outra, até porque exsurge impossível imaginar ressocialização através da segregação. Não se trata, é bom deixar bem claro, de assumir postura lírica, sustentando que não se deva utilizar a medida de internamento. Haverá casos em que comparecerá ela como necessária, mas no propósito induvidoso de buscar interromper um ciclo delinqüencial já desencadeado. Entretanto, não se imagine - por ignorância - que a instituição total seja apta a tratamento e emenda, porque a ressocialização só se dará efetivamente através de atividades no mundo externo à unidade, quando se estabelece convívio sadio - e com oportunidades - do adolescente na comunidade onde vive. A finalidade da internação é, então, estabelecer oportunidades para que o adolescente possa ter, como modo de vida, algo que não o mantenha na trilha da criminalidade.

Em outro aspecto fundamental, considerando que a contestação e o inconformismo já se dão quando se trata da medida socioeducativa de internação e, em especial, quanto aos espaços destinados à execução da mesma, o que se dizer então da aplicação da proposta aos adolescentes autores de atos infracionais da sanção penal (com seu caráter meramente retributivo) e estabelecer o sistema penitenciário brasileiro como o local para o cumprimento da mesma? É também sob essa ótica que deve ser analisada a matéria referente à imputabilidade penal, traduzindo-se na seguinte indagação: que benefícios adviriam - para o adolescente, a sociedade e o próprio sistema de Justiça - com a diminuição da imputabilidade penal? Na verdade, contaria-se com a seguintes opções: manter os adolescentes entre 16 e 18 anos submetidos a julgamento pela Justiça da Infância e da Juventude e sujeitos às medidas socioeducativas ou, de outro lado, passar a submetê-los à Justiça Penal e suas respectivas sanções. Mas aqui, sem se afastar da realidade e dos ideais de justiça, há que se levar em consideração - e criticamente - o tipo de sistema penitenciário (ou até justiça penal) para o qual se pretende encaminhar esses adolescentes.

Em conferência recentemente realizada, o professor Francisco de Assis Toledo informava que no sistema penitenciário brasileiro há cerca de quarenta mil vagas. Não obstante, se for olhá-las sob a ótica da Lei de Execuções Penais, é de se duvidar da existência de tantas vagas, porque por certo foram desconsideradas em tal levantamento as exigências legais quanto às celas, que devem ser individuais e com determinada metragem mínima. De qualquer sorte, imaginando-se que existam mesmo tais vagas, há hoje, integrando a população carcerária, perto de cento e vinte e cinco mil presos. A superpopulação corresponde, portanto, a três vezes mais do que a capacidade do próprio sistema. E pior do que isso: são aproximadamente trezentos mil os mandados de prisão não cumpridos, de pessoas para quem a resposta da justiça apenas foi no sentido da obrigatoriedade da privação de liberdade e que estão andando por aí como se nada tivesse acontecido.

Insista-se na pergunta: deve-se continuar defendendo a proposta do Estatuto da Criança e do Adolescente das pequenas unidades de internação fiscalizadas pelo Ministério Público, com um corpo técnico qualificado, permitindo a realização de atividades externas, contemplando a possibilidade de reinserção no sistema educacional, acesso ao mercado de trabalho etc. (enfim, buscando estabelecer um novo projeto de vida em conflito com a lei) ou optar pela resposta do Direito Penal, em que o adolescente, entre 16 e 18 anos, 
vá ser mais um número no contexto da população carcerária (com a promiscuidade que lhe é inerente) ou na cifra dos trezentos mil mandados de prisão não cumpridos, para a sua sorte e da própria sociedade (porque, convenha-se, é menos ruim que ele fique em liberdade, sem a execução da respectiva pena, do que venha a integrar o falido sistema penitenciário brasileiro e dele regressar como cidadão de pior categoria)?

A resposta que se quer então colher dos membros da Instituição incumbida da defesa dos valores sociais mais significativos (e que, frise-se, já rompeu definitivamente com as suas raízes de patrocinador dos interesses dos reis e dos poderosos para se constituir assim na legítima defensora da sociedade, com a visão clara de que tal tarefa importa defender prioritariamente aqueles que se encontram afastados da possibilidade de exercício dos direitos elementares da cidadania) é a de que nada justifica a diminuição da imputabilidade penal, seja pelo prisma do princípio da proteção integral como informador de toda legislação pertinente à infância e juventude (e a Associação Brasileira de Magistrados e Promotores de Justiça da Infância e da Juventude, em todos os seus Congressos, registra conclusão nesse sentido), seja no aspecto de medida relacionada à política criminal (e o próprio Conselho Nacional de Política Criminal e Penitenciária, acolhendo parecer do penalista Rolf Koerner Júnior, pronunciou-se de maneira contrária à Proposta de Emenda à

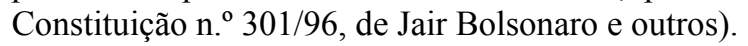

Cabe destaque também ao posicionamento unânime pelos juristas participantes da Oficina ad hoc, do III Seminário Latino-Americano sobre os Direitos da Criança, no sentido da manutenção do artigo 228, da Constituição Federal (e cujas conclusões serão encampandas na próxima tese).

Por fim, a certeza de que a manifestação do XIII Congresso Nacional do Ministério Público acerca do presente tema - assim como dos demais levados à sua deliberação - estará a contribuir para o alcance daquilo que é indicado como um dos objetivos fundamentais da República Federativa do Brasil: o de construir uma sociedade livre, justa e solidária.

\section{Conclusões}

1. A regra do artigo 228, da Constituição Federal, corresponde à cláusula pétrea e, portanto, implica limitação expressa e material ao poder reformador, nos exatos termos do artigo 60, 4. ${ }^{\text {, }}$, da Carta Magna.

2. A inimputabilidade não significa irresponsabilidade e impunidade, ficando os adolescentes autores de atos infracionais sujeitos às medidas socioeducativas, previstas no Estatuto da Criança e do Adolescente.

3. É necessária imediata implantação ou implementação dos programas relativos às medidas socioeducativas, que se têm mostrado, nos locais onde foram corretamente instalados, aptos a ser resposta social justa e adequada à prática de atos infracionais por adolescentes, com eficiência maior que a pura e simples retribuição penal e o conseqüente ingresso do jovem no sistema penitenciário.

4. Para efetivo combate à criminalidade infanto-juvenil, é indispensável a adoção de todas as medidas políticas e administrativas (e também judiciais) no sentido de distribuição da justiça social, de modo a universalizar o acesso às políticas sociais públicas (cumprindo-se o comando constitucional da prioridade absoluta em favor das crianças e adolescentes).

5. A fixação da imputabilidade penal a partir dos 18 anos de idade tem por fundamento critério de justiça e de política criminal adequados à realidade brasileira, devendo haver por parte do Ministério Público defesa intransigente da sua manutenção em sede constitucional. 